\title{
The role of perceived barriers in explaining socio-economic status differences in adherence to the fruit, vegetable and fish guidelines in older adults: a mediation study
}

\author{
S Coosje Dijkstra ${ }^{1, *}$, Judith E Neter ${ }^{1}$, Maartje $M$ van Stralen ${ }^{1,2}$, Dirk L Knol ${ }^{3}$, \\ Ingeborg A Brouwer ${ }^{1}$, Martijn Huisman ${ }^{3,4,5}$ and Marjolein Visser ${ }^{1,3}$ \\ 'Department of Health Sciences and the EMGO Institute for Health and Care Research, Faculty of Earth and Life \\ Sciences, VU University Amsterdam, De Boelelaan 1085, 1081 HV Amsterdam, The Netherlands: ${ }^{2}$ Department of \\ Public and Occupational Health, VU University Medical Center, Amsterdam, The Netherlands: ${ }^{3}$ Department of \\ Epidemiology and Biostatistics and the EMGO Institute for Health and Care Research, Faculty of Earth and Life \\ Sciences, VU University Amsterdam, Amsterdam, The Netherlands: ${ }^{4}$ Department of Sociology, VU University \\ Amsterdam, Amsterdam, The Netherlands: ${ }^{5}$ Department of Psychiatry, VU University Medical Center, Amsterdam, \\ The Netherlands
}

Submitted 8 October 2013: Final revision received 17 June 2014: Accepted 19 June 2014: First published online 4 August 2014

\begin{abstract}
Objective: We aimed to identify barriers for meeting the fruit, vegetable and fish guidelines in older Dutch adults and to investigate socio-economic status (SES) differences in these barriers. Furthermore, we examined the mediating role of these barriers in the association between SES and adherence to these guidelines. Design: Cross-sectional.

Setting: Longitudinal Aging Study Amsterdam (LASA), the Netherlands.

Subjects: We used data from 1057 community-dwelling adults, aged 55-85 years. SES was measured by level of education and household income. An FFQ was used to assess dietary intake and barriers were measured with a self-reported lifestyle questionnaire.

Results: Overall, $48.9 \%$ of the respondents perceived a barrier to adhere to the fruit guideline, $40.0 \%$ for the vegetable and $51.1 \%$ for the fish guideline. The most frequently perceived barriers to meet the guidelines were the high price of fruit and fish and a poor appetite for vegetables. Lower-SES groups met the guidelines less often and perceived more barriers. The association between income and adherence to the fruit guideline was mediated by 'perceiving any barrier to meet the fruit guideline' and the barrier 'dislike fruit'. The association between income and adherence to the fish guideline was mediated by 'perceiving any barrier to meet the fish guideline' and the barrier 'fish is expensive'.

Conclusions: Perceived barriers for meeting the dietary guidelines are common in older adults, especially in lower-SES groups. These barriers and in particular disliking and cost concerns explained the lower adherence to the guidelines for fruit and fish in lower-income groups in older adults.
\end{abstract}

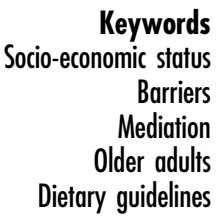

Reducing socio-economic health inequalities is an important challenge, since a low socio-economic status (SES) continues to increase the risk of chronic diseases and early death, also among older adults ${ }^{(1,2)}$. One mechanism through which SES influences health inequalities is dietary intake. Diets low in fruit, vegetables and fish are associated with higher mortality risk worldwide ${ }^{(3-5)}$ and an increased risk of CVD, obesity, type 2 diabetes and certain types of cancer ${ }^{(6-9)}$. Lower-SES groups have a greater tendency to consume unhealthy diets and meet the dietary guidelines less often than higher-SES groups ${ }^{(10,11)}$. These
SES differences are also found among older adults ${ }^{(12,13)}$ Information on underlying mechanisms that explain these SES inequalities in dietary intake is needed. This information may contribute to the prevention of diet-related chronic diseases and SES differences in these diseases.

To increase fruit, vegetable and fish intake in the general population, barriers to healthy eating have been identified, including disliking, limited cooking skills, no time to prepare healthy food, perception of high costs, no availability or no motivation to change eating habits ${ }^{(14-17)}$. SES differences in these barriers have also been described, where low-income 
groups spend less money on healthy foods than higherincome groups ${ }^{(15,18)}$ and low-education groups lack knowledge about healthy eating compared with highereducation groups ${ }^{(19)}$. Despite the fact that it is important to investigate SES differences in barriers to healthy eating, research among older adults is scarce. Older adults may face specific age-related barriers such as loss of appetite, chewing problems, decreased mobility and limited transport that may all negatively influence food choice and food intake ${ }^{(20-23)}$. It is not clear from the literature if the impact of SES on healthy eating and barriers is also present in older adults.

The aim of our study was to identify the main barriers for meeting the fruit, vegetable and fish guidelines in older adults and to examine SES differences in these barriers. More importantly, we tested if specific barriers mediate the association between SES and adherence to the fruit, vegetable and fish guidelines.

\section{Methods}

\section{Respondents}

We used data from the Longitudinal Aging Study Amsterdam (LASA), an ongoing cohort study originally designed to investigate changes in autonomy and well-being in the ageing population in the Netherlands ${ }^{(24)}$. In summary, a random sample stratified by age, sex and expected 5-year mortality was drawn from the population registers of eleven municipalities in three geographical areas in the Netherlands. In 1992-1993, 3805 individuals were enrolled in the baseline examination (response rate 60\%). In 2002-2003, a new cohort of 1002 individuals aged 55-65 years was added to the study using the same sampling procedures (response rate $55 \%$ ). Examinations were repeated every 3 years. The source population for the current study consisted of 2165 LASA respondents who participated in the general LASA cycle 2005-2006. They were invited to participate in the LASA Lifestyle Study, a side study conducted in 2007. Eligibility criteria were: age $<80$ years, independently living and cognitively well-functioning (Mini Mental State Examination score $>23$ ). In total 1421 respondents met these criteria, of whom 1058 completed a selfadministered lifestyle questionnaire (response rate $74.5 \% ; 326$ no response, eighteen refused, eight were not able due to physical problems and eleven were deceased). We excluded one person because all dietary data were missing. The study was conducted according to the guidelines laid down in the Declaration of Helsinki and all procedures involving human subjects/patients were approved by the Medical Ethical Committee of the VU Medical Center in Amsterdam, the Netherlands. All respondents gave informed consent.

\section{Socio-economic indicators}

We used net monthly household income and level of education as indicators of $\mathrm{SES}^{(25)}$. For household income, we presented several categories of income ranges and asked respondents to indicate the category that corresponded best with their own income. To those who indicated to have a partner with their own income, it was asked whether they could indicate the net income of them together. Net monthly household income was categorized as: high (>1816€), middle (1135-1816€) and low (<1135€). The middle income category covered the Dutch net modal household income of $2007^{(26)}$. For level of education, respondents were asked to indicate the highest level of education that was completed. They could choose from nine categories (no education completed to scientific education). Based on the Dutch education system and transition to the labour market, we defined three levels of education: high (university, college, higher vocational, general secondary, and intermediate vocational education); middle (general intermediate, and lower vocational education); and low (elementary education or less). For respondents with a partner living in the same household, total household income was multiplied by 0.7 to compare incomes of multi-person households with those of singleperson households ${ }^{(27)}$. Missing values for income ( $n$ 48, $4.5 \%$ ) were replaced by the most common sex-specific income category.

\section{Potential mediating barriers}

We measured the perceived barriers to meet the fruit guideline by asking respondents, "Which of the following factors are barriers for you to eat two pieces of fruit per day?' Respondents were asked to indicate, from a list of twelve barriers, the two barriers that were most important for their situation. We asked the same questions for barriers to meet the guidelines for vegetables $(\geq 200 \mathrm{~g} / \mathrm{d})$ and fish (twice weekly). Items were derived from previous research that investigated barriers to healthy eating ${ }^{(28,29)}$ and presented in Tables 2, 3 and 4. Respondents could also indicate the option 'Other, being...' and fill out their barrier. We created three composed variables that indicated if respondents perceived any barrier to meet the fruit, vegetable and fish guideline, respectively (yes/no). Respondents were categorized as 'no' if they indicated not to perceive any barriers in the 'Other, being...' option or did not choose any of the presented barriers from the list.

Age-related barriers included depressive symptoms, walk disability and co-morbidity. For depressive symptoms, we used the Dutch translation of the Centre for Epidemiologic Studies Depression scale, with scores ranging from 0 to $60^{(30)}$. A score of $\geq 16$ indicated depressive symptoms ${ }^{(31)}$. We measured the presence of walk disability with the question, 'Can you walk outside during five minutes without stopping?' We created two categories: 'yes' (no walking, or only with help and difficulties) and 'no' (I can walk without difficulties). Co-morbidity was measured by the number of self-reported chronic diseases including chronic nonspecific lung disease, cardiac disease, peripheral arterial disease, diabetes mellitus, stroke, arthritis and/or cancer. We 
created two categories to define co-morbidity: 'no' (no chronic diseases) and 'yes' (one or more chronic diseases).

\section{Adherence to the fruit, vegetable and fish guidelines}

We assessed the intakes of fruit, vegetables and fish by means of a food frequency method to derive information on the consumed frequency and number of food items. This method has shown to be a valid, inexpensive and easy tool to provide a reasonably accurate ranking of intake and to identify persons with a low intake ${ }^{(32,33)}$ Respondents indicated how many days per week they usually consumed fruit. They could choose from nine response categories ranging from 'never' to 'every day'. Next, respondents were asked for the number of portions they consumed per day ranging from 'less than one' to 'more than five portions'. To illustrate one portion of fruit written examples were given (one medium-sized apple, two mandarins or a handful of grapes). Respondents also indicated the frequency and number of glasses of fruit juice (fresh/bottled) per day. In addition, respondents indicated how many days per week they usually consumed raw vegetables (lettuce/salads) and cooked/baked vegetables (fresh/tinned, including hotchpotches and pre-packaged meals) where they could choose from nine response categories ranging from 'never' to 'every day'. Next, respondents were asked for the amount of vegetables consumed per day. The amount was expressed in number of serving spoons, which represents $50 \mathrm{~g}$ of vegetables per spoon, with seven response categories ranging from 'less than one' to 'more than five spoons'. Lastly, respondents indicated how many days per week they usually consumed fish, with nine response categories ranging from 'never' to 'every day'. This is similar to the method used in the national Food Consumption Survey. Even more importantly, the Dutch fish guideline recommendations are in frequencies and not in amount of fish consumed.

Based on the self-reported dietary intake data, we calculated adherence to the Dutch dietary guidelines for fruit, vegetables and fish. The following criteria were used: (i) two portions of fruit per day (a maximum of one glass of fruit juice $(200 \mathrm{ml})$ to replace one portion of fruit); (ii) four serving spoons of vegetables per day ( $200 \mathrm{~g}$ ); and (iii) fish twice per week ${ }^{(24)}$. In accordance with these guidelines, we did not count potatoes as a vegetable.

\section{Covariates}

Sociodemographic factors included sex, age and region of the Netherlands (west, north and south). Lifestyle factors included BMI, physical activity in the past two weeks, smoking status and alcohol consumption during the past year. We calculated BMI as measured weight (in kilograms) divided by the square of measured height (in metres squared). We defined physical activity as the average number of minutes of physical activity performed per day including walking, cycling, gardening, performing heavy housework and a maximum of two sports activities ${ }^{(34)}$. We defined smoking into three categories: current, former and never smoking. Never smokers included former smokers who stopped smoking more than 15 years ago. Categories of alcohol consumption included: no drinking, moderate drinking (less than three glasses per day) and (very) excessive drinking (three or more glasses per day). Partner status was defined as 'yes' (presence of a partner in the household) or 'no' (no partner in the household).

\section{Statistical analyses}

We used descriptive statistics to summarize the characteristics of the respondents. Continuous variables were presented as means and standard deviations, whereas categorical variables were presented as relative frequencies. We calculated the frequencies for the barriers to meet the fruit, vegetable and fish guidelines and performed Fischer's exact tests to test for statistically significant differences between SES groups. This test can handle very low cell frequencies.

We scaled the SES indicators as continuous rank scores. Applying these rank scores allows for estimating the relative index of inequality (RII), which enables direct comparison between the two SES indicators ${ }^{(35)}$. To calculate the RII, a score between 0 (highest SES) and 1 (lowest SES) was assigned to each answer category based on the proportion of respondents above the midpoint in that category with a higher position in the SES hierarchy (for level of income and education separately). For example, if $10 \%$ of the respondents were in the highest education category, respondents in this group were represented by the range $0-0 \cdot 1$ and were allocated the score $0.05(0 \cdot 1 / 2)$. If $20 \%$ of the respondents were in the next group, then this education group was allocated the score $0 \cdot 20(0 \cdot 1+0 \cdot 2 / 2)$ and so on. The RII was then obtained by performing the regression of the outcome $v$. each of the continuous SES rank scores, and can be interpreted as the odds ratio comparing the most with the least deprived measure of SES.

To assess the barriers as potential mediating variables in the association between SES and adherence to the guidelines for fruit, vegetables and fish, we conducted structural equation modelling using Mplus software (Fig. 1). We estimated the mediation models separately for income and education levels and for adherence to the fruit, the vegetable and the fish guideline. First, the regression of the SES indicators $v$. adherence to the fruit, vegetable and fish guideline was performed ( $c$ path $=$ total effect). Path $a$ represents the association between the SES indicator and the potential mediating barrier, while path $b$ represents the association between the potential mediating barrier and adherence to the dietary guideline, adjusted for the SES indicators. Thereafter, the association between the SES indicators and adherence to the fruit, vegetable or fish guideline was examined adjusted for the potential mediating barrier $\left(c^{\prime}\right.$ path $=$ direct effect $)$. The mediation effect $(a \times b)$ was calculated for each mediator separately. Weighted least 
squares with means and variance adjusted (WLSMV) estimates were used as the estimation method with bootstrapped confidence intervals. The probit regression coefficient $(B)$ can be interpreted as an odds ratio by calculating $\exp (1.7 \times B)=\mathrm{OR}$.

We evaluated potential confounding by adding covariates individually to the sex- and age-adjusted models and compared the adjusted estimate with the sex- and age-adjusted estimate. We included variables when they changed the

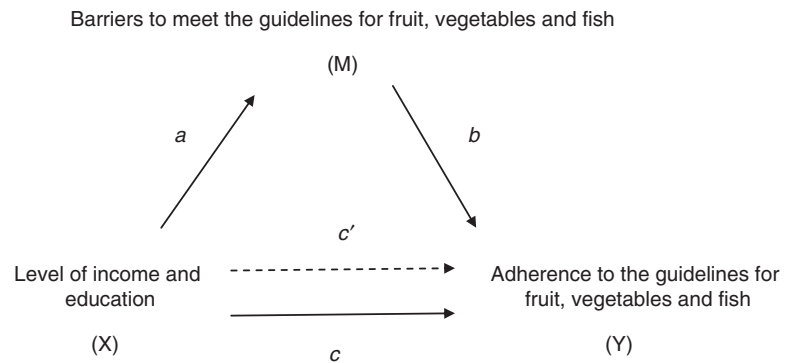

Fig. 1 Mediation models for the association between level of income and education and adherence to the fruit, vegetable and fish guidelines. $X$ is the independent variable, $Y$ is the dependent variable and $M$ is the mediator. Path a represents the association between $X$ and $M$ and path $b$ represents the association between $M$ and $Y$, adjusted for $X$. Path $c^{\prime}$ is the direct effect and path $c$ is the total effect between $X$ and $Y$ estimate $(B)$ by $10 \%$ or more, which resulted in additional adjustments for presence of a partner in the household and alcohol consumption. We also adjusted the analyses for the other SES indicator. By adjusting simultaneously we investigated the independent associations of the barrier with the SES indicator in question. $P<0.05$ was considered statistically significant. Statistical analyses were performed using the statistical software package IBM SPSS Statistics for Windows version 20.0 and Mplus version 6.11.

\section{Results}

\section{Characteristics}

The total sample included 1057 participants, 555 women and 502 men, with a mean age of 68.9 (SD 6.2) years (Table 1). More than half of the respondents had both a middle level of education and a middle level of income. Of the sample, $82.5 \%$ reported to adhere to the fruit guideline, $65.1 \%$ to the vegetable guideline and $31.7 \%$ to the fish guideline.

\section{Barriers}

Almost half $(48.9 \%, n$ 485) of the respondents perceived any barrier to meet the fruit guideline (Table 2). Most

Table 1 Characteristics of 1057 older Dutch participants of the Longitudinal Aging Study Amsterdam

\begin{tabular}{|c|c|c|c|}
\hline & $n \dagger$ & $\%$ or mean & SD or IQR \\
\hline Female sex (\%) & 1057 & 52.5 & - \\
\hline Age (years), mean and SD & 1057 & 68.9 & $6 \cdot 2$ \\
\hline \multicolumn{4}{|l|}{ Region of the Netherlands (\%) } \\
\hline West & 438 & $41 \cdot 5$ & - \\
\hline North & 377 & $35 \cdot 7$ & - \\
\hline South & 242 & 22.9 & - \\
\hline \multicolumn{4}{|l|}{ Education (\%) } \\
\hline Low & 231 & 21.9 & - \\
\hline Middle & 607 & $57 \cdot 4$ & - \\
\hline High & 219 & $20 \cdot 7$ & - \\
\hline \multicolumn{4}{|l|}{ Income (\%) } \\
\hline Low & 249 & $23 \cdot 6$ & - \\
\hline Middle & 665 & 62.9 & - \\
\hline High & 143 & $13 \cdot 5$ & - \\
\hline BMI $\left(\mathrm{kg} / \mathrm{m}^{2}\right)$, mean and SD & 1040 & $27 \cdot 5$ & $4 \cdot 1$ \\
\hline \multicolumn{4}{|l|}{ Smoking (\%) } \\
\hline Never smoked & 391 & $37 \cdot 3$ & - \\
\hline Former & 491 & $46 \cdot 8$ & - \\
\hline Current & 167 & $15 \cdot 9$ & - \\
\hline \multicolumn{4}{|l|}{ Alcohol consumption (\%) } \\
\hline Non-drinker & 229 & $21 \cdot 7$ & - \\
\hline Moderate & 590 & $55 \cdot 8$ & - \\
\hline (Very) excessive & 238 & $22 \cdot 5$ & - \\
\hline Partner in the household, yes (\%) & 1057 & $78 \cdot 4$ & - \\
\hline Physical activity $(\min / \mathrm{d})$, median and IQR & 1055 & $62 \cdot 0$ & $30-108$ \\
\hline Depressive symptoms, CES-D $\geq 16(\%)$ & 1057 & $8 \cdot 1$ & - \\
\hline Walk disability (\%) & 1055 & $9 \cdot 6$ & - \\
\hline Co-morbidity, $\geq 1$ chronic disease (\%) & 1057 & $50 \cdot 9$ & - \\
\hline \multicolumn{4}{|l|}{ Adherence to the guidelines (\%) } \\
\hline Fruit $(\geq 2$ pieces/d) & 997 & $82 \cdot 5$ & - \\
\hline Vegetables $(\geq 200 \mathrm{~g} / \mathrm{d})$ & 965 & $65 \cdot 1$ & - \\
\hline Fish ( $\geq 2$ times/week) & 1050 & $31 \cdot 7$ & - \\
\hline
\end{tabular}

IQR, interquartile range; CES-D, Centre for Epidemiologic Studies Depression scale.

$\dagger n$ total sample (sample sizes vary due to missing data). 
Table 2 Perceived barriers to meet the fruit guideline by income and education levels in 1010 older Dutch participants of the Longitudinal Aging Study Amsterdam

\begin{tabular}{|c|c|c|c|c|c|c|c|c|c|c|c|c|c|c|}
\hline & \multirow{2}{*}{\multicolumn{2}{|c|}{ Total }} & \multicolumn{6}{|c|}{ Level of income } & \multicolumn{6}{|c|}{ Level of education } \\
\hline & & & \multicolumn{2}{|c|}{ Low } & \multicolumn{2}{|c|}{ Middle } & \multicolumn{2}{|c|}{ High } & \multicolumn{2}{|c|}{ Low } & \multicolumn{2}{|c|}{ Middle } & \multicolumn{2}{|c|}{ High } \\
\hline & $n$ & $\%$ & $n$ & $\%$ & $n$ & $\%$ & $n$ & $\%$ & $n$ & $\%$ & $n$ & $\%$ & $n$ & $\%$ \\
\hline $\begin{array}{l}\text { Perceiving any barrier to meet the fruit guideline } \\
\text { Specific barriers }\end{array}$ & 485 & $48 \cdot 9$ & 130 & 54.6 & 297 & $46 \cdot 8$ & $58^{*}$ & $42 \cdot 0$ & 115 & $51 \cdot 3$ & 275 & $47 \cdot 3$ & 95 & $46 \cdot 3$ \\
\hline Fruit is expensive & 106 & $10 \cdot 5$ & 43 & $18 \cdot 1$ & 53 & $8 \cdot 3$ & $10^{*}$ & $7 \cdot 3$ & 34 & $15 \cdot 2$ & 62 & $10 \cdot 7$ & $10^{*}$ & 4.9 \\
\hline Fruit spoils quickly & 76 & 7.5 & 18 & 7.6 & 48 & $7 \cdot 6$ & 10 & $7 \cdot 2$ & 28 & $12 \cdot 5$ & 39 & $6 \cdot 7$ & $9^{*}$ & 4.4 \\
\hline Recommendations for fruit are not clear & 21 & $2 \cdot 1$ & 5 & $2 \cdot 1$ & 15 & $2 \cdot 4$ & 1 & $0 . \overline{7}$ & 2 & 0.9 & 15 & 2.6 & 4 & $2 \cdot 0$ \\
\hline Eating fruit is impractical & 46 & 4.6 & 6 & 2.5 & 33 & $5 \cdot 2$ & 7 & $5 \cdot 1$ & 5 & $2 \cdot 2$ & 25 & 4.3 & $16^{*}$ & $7 \cdot 8$ \\
\hline Difficult to find tasty fruit & 54 & $5 \cdot 3$ & 18 & $7 \cdot 6$ & 31 & 4.9 & 5 & 3.6 & 17 & $7 \cdot 6$ & 29 & $5 \cdot 0$ & 8 & 3.9 \\
\hline Dislike fruit & 35 & 3.5 & 13 & $5 \cdot 5$ & 18 & $2 \cdot 8$ & 4 & 2.9 & 7 & $3 \cdot 1$ & 22 & 3.8 & 6 & 2.9 \\
\hline Fruit is difficult to store & 82 & $8 \cdot 1$ & 24 & $10 \cdot 1$ & 53 & 8.4 & 5 & 3.6 & 24 & $10 \cdot 7$ & 45 & $7 \cdot 7$ & 13 & $6 \cdot 3$ \\
\hline It takes time to buy fruit & 19 & 1.9 & 7 & 2.9 & 9 & 1.4 & 3 & $2 \cdot 2$ & 6 & $2 \cdot 7$ & 6 & 1.0 & 7 & 3.4 \\
\hline Concerns about the pesticide residues on fruit & 66 & 6.5 & 13 & 5.5 & 42 & $6 \cdot 6$ & 11 & $8 \cdot 0$ & 13 & $5 \cdot 8$ & 39 & $6 \cdot 7$ & 14 & $6 \cdot 8$ \\
\hline Poor appetite & 59 & $5 \cdot 8$ & 20 & 8.4 & 32 & $5 \cdot 0$ & 7 & $5 \cdot 1$ & 21 & $9 \cdot 4$ & 29 & $5 \cdot 0$ & $9^{*}$ & 4.4 \\
\hline Troubles with chewing fruit & 25 & $2 \cdot 5$ & 10 & $4 \cdot 2$ & 14 & $2 \cdot 2$ & 1 & 0.7 & 5 & $2 \cdot 2$ & 14 & 2.4 & 6 & 2.9 \\
\hline Eating out often & 10 & 1.0 & 1 & 0.4 & 4 & 0.6 & $5^{\star}$ & 3.6 & 0 & 0.0 & 7 & $1 \cdot 2$ & 3 & 1.5 \\
\hline Other & 96 & 9.5 & 20 & 8.4 & 62 & $9 \cdot 8$ & 14 & $10 \cdot 1$ & 16 & $7 \cdot 1$ & 60 & $10 \cdot 3$ & 20 & 9.8 \\
\hline
\end{tabular}

${ }^{*} P<0.05$ indicates statistically significant difference in perceived barriers within income and education levels.

Table 3 Perceived barriers to meet the vegetable guideline by income and education levels in 1013 older Dutch participants of the Longitudinal Aging Study Amsterdam

\begin{tabular}{|c|c|c|c|c|c|c|c|c|c|c|c|c|c|c|}
\hline & & & \multicolumn{6}{|c|}{ Level of income } & \multicolumn{6}{|c|}{ Level of education } \\
\hline & \multicolumn{2}{|c|}{ Total } & \multicolumn{2}{|c|}{ Low } & \multicolumn{2}{|c|}{ Middle } & \multicolumn{2}{|c|}{ High } & \multicolumn{2}{|c|}{ Low } & \multicolumn{2}{|c|}{ Middle } & \multicolumn{2}{|c|}{ High } \\
\hline & $n$ & $\%$ & $n$ & $\%$ & $n$ & $\%$ & $n$ & $\%$ & $n$ & $\%$ & $n$ & $\%$ & $n$ & $\%$ \\
\hline $\begin{array}{l}\text { Perceiving any barrier to meet the vegetable guideline } \\
\text { Specific barriers }\end{array}$ & 405 & $40 \cdot 0$ & 112 & $46 \cdot 9$ & 246 & $38 \cdot 7$ & $47^{*}$ & $34 \cdot 1$ & 106 & $48 \cdot 0$ & 224 & $38 \cdot 2$ & $75^{\star}$ & $36 \cdot 4$ \\
\hline Vegetables are expensive & 83 & 8.2 & 34 & $14 \cdot 2$ & 43 & $6 \cdot 8$ & $6^{*}$ & 4.3 & 25 & $11 \cdot 3$ & 54 & 9.2 & $4^{*}$ & 1.9 \\
\hline Vegetables spoil quickly & 43 & 4.2 & 14 & 5.9 & 24 & 3.8 & 5 & 3.6 & 16 & $7 \cdot 2$ & 20 & 3.4 & 7 & 3.4 \\
\hline Eating vegetables is impractical & 6 & 0.6 & 1 & 0.4 & 4 & 0.6 & 1 & 0.7 & 0 & 0.0 & 5 & 0.9 & 1 & 0.5 \\
\hline Difficult to find tasty vegetables & 55 & $5 \cdot 4$ & 17 & $7 \cdot 1$ & 37 & $5 \cdot 8$ & $1 *$ & 0.7 & 16 & $7 \cdot 2$ & 13 & $5 \cdot 6$ & 6 & 2.9 \\
\hline Dislike vegetables & 24 & $2 \cdot 4$ & 4 & 1.7 & 16 & $2 \cdot 5$ & 4 & 2.9 & 5 & $2 \cdot 3$ & 12 & $2 \cdot 0$ & 7 & 3.4 \\
\hline Recommendations for vegetables are not clear & 20 & 2.0 & 4 & 1.7 & 16 & 2.5 & 0 & 0.0 & 4 & 1.8 & 14 & $2 \cdot 4$ & 2 & 1.0 \\
\hline It is difficult to store vegetables & 62 & $6 \cdot 1$ & 20 & 8.4 & 36 & 5.7 & 6 & $4 \cdot 3$ & 20 & 9.0 & 30 & $5 \cdot 1$ & 12 & $5 \cdot 8$ \\
\hline It takes a lot of time to prepare vegetables & 61 & $6 \cdot 0$ & 12 & $5 \cdot 0$ & 36 & $5 \cdot 7$ & 13 & $9 \cdot 4$ & 14 & $6 \cdot 3$ & 28 & $4 \cdot 8$ & 19 & $9 \cdot 2$ \\
\hline Concerns about the pesticide residues on vegetables & 64 & $6 \cdot 3$ & 18 & 7.5 & 35 & 5.5 & 11 & 8.0 & 10 & 4.5 & 41 & $7 \cdot 0$ & 13 & $6 \cdot 3$ \\
\hline Poor appetite & 104 & $10 \cdot 3$ & 27 & $11 \cdot 3$ & 64 & $10 \cdot 1$ & 13 & $9 \cdot 4$ & 32 & 14.5 & 56 & $9 \cdot 6$ & 16 & $7 \cdot 8$ \\
\hline Troubles with chewing vegetables & 12 & 1.2 & 6 & 2.5 & 6 & 0.9 & 0 & 0.0 & 3 & 1.4 & 7 & 1.2 & 2 & 1.0 \\
\hline Eating out often & 24 & 2.4 & 3 & 1.3 & 14 & $2 \cdot 2$ & 7 & $5 \cdot 1$ & 2 & 0.9 & 15 & 2.6 & 7 & 3.4 \\
\hline Persons with whom I eat do not like vegetables & 16 & 1.6 & 4 & $1 \cdot 7$ & 10 & 1.6 & 2 & 1.4 & 6 & $2 \cdot 7$ & 9 & 1.5 & 1 & 0.5 \\
\hline Other & 45 & 4.4 & 11 & $4 \cdot 6$ & 28 & 4.4 & 6 & $4 \cdot 3$ & 11 & $5 \cdot 0$ & 21 & 3.6 & 13 & $6 \cdot 3$ \\
\hline
\end{tabular}

${ }^{*} P<0.05$ indicates statistically significant difference in perceived barriers within income and education levels.

reported fruit barriers were 'fruit is expensive' $(10.5 \%, n$ 106), 'fruit is difficult to store' $(8 \cdot 1 \%, n 82)$ and 'fruit spoils quickly' (7.5\%, $n$ 76). 'Eating out often' (1.0\%, $n$ 10), 'it takes time to buy fruit' (1.9\%, $n$ 19) and 'recommendations for fruit are not clear' $(2 \cdot 1 \%, n 21)$ were mentioned by only a very small proportion of the respondents.

Perceiving any barrier to meet the vegetable guideline was reported by $40 \cdot 0 \%$ ( $n$ 405) of the respondents (Table 3 ). Most reported vegetable barriers were 'poor appetite' $(10.3 \%, n 104)$, 'vegetables are expensive' ( $8.2 \%, n$ 83) and 'concerns about pesticide residues on vegetables' ( $6.3 \%$, $n$ 64). 'Eating vegetables is impractical' (0.6\%, n 6), 'troubles with chewing vegetables' $(1 \cdot 2 \%, n 12)$ and 'persons with whom I eat do not like vegetables' (1.6, $n$ 16) were mentioned by only a very small proportion of the respondents.

Perceiving any barrier to meet the fish guideline was reported by $51 \cdot 1 \%(n 525)$ of the older adults (Table 4$)$. Most reported fish barriers were 'fish is expensive' ( $32.1 \%$, $n$ 237), 'habits and tradition' (20.1\%, $n$ 206) and 'persons with whom I eat do not like fish' (9.5\%, $n$ 97). 'Recommendations for fish are not clear' (1.9\%, $n$ 19), 'fish spoils quickly' $(3.1 \%, n 32)$ and 'concerns about unwanted materials in fish' $(3.1 \%, n 32)$ were mentioned by only a very small proportion of the respondents. 
Table 4 Perceived barriers to meet the fish guideline by income and education levels in 1013 older Dutch participants of the Longitudinal Aging Study Amsterdam

\begin{tabular}{|c|c|c|c|c|c|c|c|c|c|c|c|c|c|c|}
\hline & & & \multicolumn{6}{|c|}{ Level of income } & \multicolumn{6}{|c|}{ Level of education } \\
\hline & \multicolumn{2}{|c|}{ Total } & \multicolumn{2}{|c|}{ Low } & \multicolumn{2}{|c|}{ Middle } & \multicolumn{2}{|c|}{ High } & \multicolumn{2}{|c|}{ Low } & \multicolumn{2}{|c|}{ Middle } & \multicolumn{2}{|c|}{ High } \\
\hline & $n$ & $\%$ & $n$ & $\%$ & $n$ & $\%$ & $n$ & $\%$ & $n$ & $\%$ & $n$ & $\%$ & $n$ & $\%$ \\
\hline $\begin{array}{l}\text { Perceiving any barrier to meet the fish guideline } \\
\text { Specific barriers }\end{array}$ & 525 & $51 \cdot 1$ & 142 & $58 \cdot 4$ & 325 & $50 \cdot 2$ & $58^{*}$ & $42 \cdot 6$ & 123 & $54 \cdot 4$ & 296 & $50 \cdot 1$ & 106 & $50 \cdot 5$ \\
\hline Fish is expensive & 237 & $32 \cdot 1$ & 86 & 35.5 & 124 & $19 \cdot 2$ & $27^{\star}$ & $19 \cdot 9$ & 67 & $29 \cdot 8$ & 139 & $23 \cdot 6$ & $31^{*}$ & $14 \cdot 8$ \\
\hline Persons with whom I eat do not like fish & 97 & 9.5 & 22 & $9 \cdot 1$ & 65 & $10 \cdot 0$ & 10 & $7 \cdot 4$ & 14 & $6 \cdot 2$ & 65 & 11 & 18 & 8.6 \\
\hline Fish spoils quickly & 32 & $3 \cdot 1$ & 10 & $4 \cdot 1$ & 16 & 2.5 & 6 & 4.4 & 11 & 4.9 & 19 & $3 \cdot 2$ & $2^{*}$ & 1.0 \\
\hline Recommendations for fish are not clear & 19 & 1.9 & 3 & $1 \cdot 2$ & 12 & 1.9 & 4 & $2 \cdot 9$ & 4 & $1 \cdot 8$ & 13 & $2 \cdot 2$ & 2 & 1.0 \\
\hline Fish bones are unpalatable & 87 & 8.5 & 26 & $10 \cdot 7$ & 49 & $7 \cdot 6$ & 12 & $8 \cdot 8$ & 21 & $9 \cdot 3$ & 48 & $8 \cdot 1$ & 18 & 8.6 \\
\hline Good-quality fish is hard to find & 5 & $5 \cdot 3$ & 12 & $5 \cdot 0$ & 35 & 5.4 & 7 & $5 \cdot 1$ & 8 & 3.6 & 32 & 5.4 & 14 & $6 \cdot 7$ \\
\hline Dislike fish & 80 & $7 \cdot 8$ & 20 & $8 \cdot 3$ & 50 & $7 \cdot 7$ & 10 & 7.4 & 16 & $7 \cdot 1$ & 45 & 7.6 & 19 & $9 \cdot 0$ \\
\hline Fish smells unpalatable & 70 & $6 \cdot 8$ & 14 & $5 \cdot 8$ & 51 & 7.9 & 5 & $3 \cdot 7$ & 19 & 8.4 & 39 & $6 \cdot 6$ & 12 & $5 \cdot 7$ \\
\hline Difficult to store fish & 39 & 3.8 & 13 & $5 \cdot 4$ & 24 & 3.7 & 2 & 1.5 & 11 & 4.9 & 27 & 4.6 & $1^{*}$ & 0.5 \\
\hline Concerns about unwanted materials in fish & 32 & $3 \cdot 1$ & 7 & 2.9 & 20 & $3 \cdot 1$ & 5 & 3.7 & 6 & $2 \cdot 7$ & 19 & 3.2 & 7 & 3.3 \\
\hline It is difficult to prepare fish & 50 & 4.9 & 13 & 5.4 & 25 & 3.9 & 12 & $8 \cdot 8$ & 14 & $6 \cdot 2$ & 23 & 3.9 & 13 & $6 \cdot 2$ \\
\hline Poor appetite & 36 & 3.5 & 17 & $7 \cdot 0$ & 18 & $2 \cdot 8$ & $1^{*}$ & 0.7 & 15 & $6 \cdot 7$ & 17 & 2.9 & $4^{*}$ & 1.9 \\
\hline Habits and tradition & 206 & $20 \cdot 1$ & 48 & $19 \cdot 8$ & 131 & $20 \cdot 0$ & 27 & 19.9 & 39 & $17 \cdot 3$ & 115 & 19.5 & 52 & 24.8 \\
\hline Other & 58 & $5 \cdot 7$ & 12 & $5 \cdot 0$ & 39 & $6 \cdot 0$ & 7 & $5 \cdot 1$ & 15 & $6 \cdot 7$ & 31 & $5 \cdot 3$ & 12 & $5 \cdot 7$ \\
\hline
\end{tabular}

${ }^{\star} P<0.05$ indicates statistically significant difference in perceived barriers within income and education levels.

Table 5 Association between income and education levels and adherence to the fruit, vegetable and fish guidelines (total effect, path $c$ ) $†$ in 1013 older Dutch participants of the Longitudinal Aging Study Amsterdam

\begin{tabular}{|c|c|c|c|c|c|c|}
\hline & \multicolumn{2}{|c|}{ Adherence to the fruit guideline } & \multicolumn{2}{|c|}{ Adherence to the vegetable guideline } & \multicolumn{2}{|c|}{ Adherence to the fish guideline } \\
\hline & $B$ & $95 \% \mathrm{Cl}$ & $B$ & $95 \% \mathrm{Cl}$ & $B$ & $95 \% \mathrm{Cl}$ \\
\hline $\begin{array}{l}\text { Level of income } \\
\text { Level of education }\end{array}$ & $\begin{array}{l}-0.40^{*} \\
-0.13\end{array}$ & $\begin{array}{l}-0.81,-0.01 \\
-0.49,0.27\end{array}$ & $\begin{array}{l}-0.02 \\
-0.70^{\star \star \star}\end{array}$ & $\begin{array}{l}-0.36,0.34 \\
-1.03,-0.36\end{array}$ & $\begin{array}{l}-0.38^{*} \\
-0.27\end{array}$ & $\begin{array}{l}-0.72,-0.02 \\
-0.58,0.07\end{array}$ \\
\hline
\end{tabular}

SES, socio-economic status.

Statistical significance of the associations: ${ }^{\star} P<0.05$, ${ }^{\star \star \star} P<0.001$.

†Adjusted for sex, age, alcohol consumption, partner status and the other SES indicator.

łLevel of income and education are scaled as relative index of inequality (score between 0 and 1 ), comparing the most with the least deprived measure of SES.

Differences in adherence to the guidelines for fruit, vegetable and fish by socio-economic status

SES differences in adherence to the guidelines are presented in Table 5 and represent path $c$ (total effect). Lower income levels were statistically significantly associated with lower adherence to the fruit guideline $(B=-0.40$, $95 \% \mathrm{CI}-0.81,-0.01)$ and the fish guideline $(B=-0.38$, $95 \%$ CI $-0.72,-0.02)$. No association between income and adherence to the vegetable guideline was observed. Lower education levels were statistically significantly associated with lower adherence to the vegetable guideline $(B=-0.70,95 \% \mathrm{CI}-1 \cdot 03,-0 \cdot 36)$. Level of education was not associated with adherence to the guidelines for fruit and fish.

\section{Differences in barriers to meet the fruit guideline by socio-economic status}

Table 2 shows the perceived barriers to meet the fruit guideline by education and income levels and Table 6 shows the regression coefficients for the associations between education and income levels, potential mediators and adherence to the guideline for fruit. Path $a$ in Table 6 indicates the association between income (column (1)) and education levels (column (2)) and the potential mediating barriers for adherence to the fruit guideline. Lower income levels were statistically significantly associated with a higher probability to perceive any barrier to meet the fruit guideline and to perceive the barriers 'fruit is expensive', 'dislike fruit', 'fruit is difficult to store', 'troubles with chewing fruit' and with having a walk disability. Lower education levels were statistically significantly associated with a higher probability to perceive the barriers 'fruit is expensive' and 'fruit spoils quickly'. Path $b$ in Table 6 (column (3)) indicates the associations between the potential mediating barriers and adherence to the fruit guideline, adjusted for the SES indicators. Perceiving any barrier to meet the fruit guideline and the barriers 'recommendations for fruit are not clear', 'eating fruit is impractical', 'difficult to find tasty fruit', 'dislike fruit', 'poor appetite', 'troubles with chewing fruit' and having one or more chronic diseases all statistically significantly lowered the probability to adhere to the fruit guideline. 
Table 6 Associations of income and education levels with perceived barriers to adherence to the fruit guideline (a path), associations of perceived barriers with adherence to the fruit guideline adjusted for the SES indicators $(b$ path) $\dagger$, association of income and education levels with adherence to the fruit guideline adjusted for the perceived barriers ( $c^{\prime}$ path) and the mediation effects for income and education levels in 1013 older Dutch participants of the Longitudinal Aging Study Amsterdam

\begin{tabular}{|c|c|c|c|c|c|c|c|c|c|}
\hline & \multirow{2}{*}{$\frac{\text { Column (1) }}{\begin{array}{c}\text { Path } a \\
\text { income }\end{array}}$} & \multirow{2}{*}{ 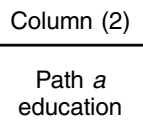 } & \multirow{2}{*}{$\begin{array}{c}\text { Column (3) } \\
\text { Path } b\end{array}$} & \multirow{2}{*}{$\frac{\text { Column (4) }}{\begin{array}{l}\text { Path } c^{\prime} \\
\text { income }\end{array}}$} & \multirow{2}{*}{$\begin{array}{c}\text { Column (5) } \\
\begin{array}{c}\text { Path } c^{\prime} \\
\text { education }\end{array}\end{array}$} & \multicolumn{2}{|c|}{ Column (6) } & \multicolumn{2}{|c|}{ Column (7) } \\
\hline & & & & & & \multicolumn{2}{|c|}{$\begin{array}{c}\text { Mediation } \\
\text { effect income }\end{array}$} & \multicolumn{2}{|c|}{$\begin{array}{c}\text { Mediation } \\
\text { effect education }\end{array}$} \\
\hline & $B$ & $B$ & $B$ & B & B & $B$ & $95 \% \mathrm{Cl}$ & B & $95 \% \mathrm{Cl}$ \\
\hline Any barrier to meet the fruit guideline & $0.41^{*}$ & 0.16 & $-0.55^{\star \star \star}$ & -0.17 & -0.05 & $-0.23^{\star}$ & $-0.39,-0.05$ & -0.09 & $-0.28,0.08$ \\
\hline Fruit is expensive & $0.64^{\star *}$ & $0.55^{*}$ & 0.10 & $-0.46^{\star}$ & -0.19 & 0.06 & $-0.04,0.23$ & 0.05 & $-0.03,0.21$ \\
\hline Fruit spoils quickly & -0.08 & $0.62^{\star}$ & 0.10 & -0.39 & -0.14 & -0.00 & $-0.07,0.04$ & 0.01 & $-0.10,0.16$ \\
\hline $\begin{array}{l}\text { Recommendations for fruit are } \\
\text { not clear }\end{array}$ & 0.21 & -0.14 & $-0.26^{\star}$ & -0.34 & -0.17 & -0.06 & $-0.33,0.13$ & 0.04 & $-0.15,0.33$ \\
\hline Eating fruit is impractical & 0.14 & -0.53 & $-0.36^{\star \star \star}$ & -0.35 & -0.32 & -0.05 & $-0.25,0.10$ & 0.19 & $0.01,0.45$ \\
\hline Difficult to find tasty fruit & 0.30 & 0.38 & $-0.29^{\star \star}$ & -0.31 & -0.03 & -0.08 & $-0.28,0.07$ & -0.11 & $-0.33,0.03$ \\
\hline Dislike fruit & $0.78^{\star}$ & -0.03 & $-0.61^{\star \star \star}$ & 0.08 & -0.15 & $-0.48^{\star}$ & $-0.96,-0.08$ & 0.02 & $-0.35,0.41$ \\
\hline Fruit is difficult to store & $0.47^{\star}$ & 0.13 & 0.06 & $-0.42^{\star}$ & -0.14 & 0.03 & $-0.05,0.18$ & 0.01 & $-0.03,0.13$ \\
\hline It takes time to buy fruit & 0.49 & -0.47 & -0.04 & -0.38 & -0.15 & -0.02 & $-0.28,0.13$ & 0.02 & $-0.12,0.30$ \\
\hline $\begin{array}{l}\text { Concerns about the pesticide } \\
\text { residues on fruit }\end{array}$ & -0.26 & 0.14 & 0.01 & -0.40 & -0.13 & 0.00 & $-0.06,0.09$ & -0.00 & $-0.07,0.05$ \\
\hline Poor appetite & 0.20 & 0.35 & $-0.45^{\star \star \star}$ & -0.31 & 0.03 & -0.09 & $-0.35,0.14$ & -0.16 & $-0.45,0.10$ \\
\hline Troubles with chewing fruit & $0.91^{*}$ & -0.67 & $-0.26^{\star}$ & -0.15 & -0.31 & -0.24 & $-0.68,0.00$ & 0.18 & $-0.02,0.54$ \\
\hline Eating out often & -1.35 & -0.26 & -0.04 & -0.45 & -0.14 & 0.06 & $-0.40,0.87$ & 0.01 & $-0.11,0.4 C$ \\
\hline \multicolumn{10}{|l|}{ Age-related barriers } \\
\hline Depressive symptoms & 0.15 & 0.39 & -0.08 & -0.38 & -0.10 & -0.01 & $-0.12,0.02$ & -0.03 & $-0.18,0.02$ \\
\hline Walk disability & $0.68^{\star *}$ & 0.23 & 0.01 & -0.40 & -0.13 & 0.00 & $-0.14,0.15$ & 0.00 & $-0.06,0.07$ \\
\hline Co-morbidity & -0.21 & 0.06 & $-0.24^{\star *}$ & $-0.45^{\star}$ & -0.12 & 0.05 & $-0.07,0.20$ & -0.01 & $-0.14,0.10$ \\
\hline
\end{tabular}

SES, socio-economic status.

Statistical significance of the associations: ${ }^{\star} P<0.05,{ }^{\star \star} P<0.01,{ }^{\star \star \star} P<0.001$.

†All associations are adjusted for sex, age, alcohol consumption, partner status and the other SES indicator.

\section{Differences in barriers to meet the vegetable guideline by socio-economic status}

Table 3 shows the perceived barriers to meet the vegetable guideline by level of education and income and Table 7 shows the regression coefficients for the associations between level of income and education, potential mediators and adherence to the guideline for vegetables. Path $a$ in Table 7 indicates the association between income (column (1)) and education levels (column (2)) and the potential mediating barriers for adherence to the vegetable guideline. Lower income levels were statistically significantly associated with a higher probability to perceive the barrier 'vegetables are expensive' and having a walk disability. Lower education levels were statistically significantly associated with a higher probability to perceive the barrier 'vegetables are expensive'. Path $b$ in Table 7 (column (3)) indicates the associations between the potential mediating barriers and adherence to the vegetable guideline, adjusted for the SES indicators. Perceiving any barrier to meet the vegetable guideline and the barriers 'difficult to find tasty vegetables', 'dislike vegetables' and 'poor appetite' all statistically significantly lowered the probability to adhere to the vegetable guideline.

\section{Differences in barriers to meet the fish guideline by socio-economic status}

Table 4 shows the perceived barriers to meet the fish guideline by level of education and income and Table 8 shows the regression coefficients for the associations between level of income and education, potential mediators and adherence to the guideline for fish. Path $a$ in Table 8 indicates the association between income (column (1)) and education levels (column (2)) and the potential mediating barriers for adherence to the fish guideline. Lower income levels were statistically significantly associated with a higher probability to perceive any barrier to meet the fish guideline and the barrier 'fish is expensive' and having a walk disability. We observed no association between level of education and any barrier to meet the fish guideline. Path $b$ in Table 8 (column (3)) indicates the associations between the potential mediating barriers and adherence to the fish guideline, adjusted for the SES indicators. Perceiving any barrier to meet the fish guideline and the barriers 'fish is expensive', 'persons with whom I eat do not like fish', 'dislike fish', 'fish smells unpalatable', 'poor appetite' and 'habits and tradition' all statistically significantly lowered the probability to adhere to the fish guideline.

\section{Potential mediators}

The mediation effects are presented in Tables 6 (fruit), 7 (vegetables) and 8 (fish) for level of income (column (6)) and education (column (7)). The association between level of income and adherence to the guideline for fruit was mediated by 'perceiving any barrier to meet the fruit guideline' (mediation effect: $B=-0 \cdot 23, P=0 \cdot 02$ ) and by the barrier 'dislike fruit' (mediation effect: $B=-0 \cdot 48$, $P=0.04)$. The association between level of income and adherence to the fish guideline was mediated by 'perceiving any barrier to meet the fish guideline' (mediation effect: 
Table 7 Associations of income and education levels with perceived barriers to adherence to the vegetable guideline (a path), associations of perceived barriers with adherence to the vegetable guideline adjusted for the SES indicators ( $b$ path)†, association of income and education levels with adherence to the vegetable guideline adjusted for the perceived barriers $\left(c^{\prime}\right.$ path) and the mediation effects for income and education levels in 1013 older Dutch participants of the Longitudinal Aging Study Amsterdam

\begin{tabular}{|c|c|c|c|c|c|c|c|c|c|}
\hline & \multirow{2}{*}{$\frac{\text { Column (1) }}{\begin{array}{c}\text { Path } a \\
\text { income }\end{array}}$} & \multirow{2}{*}{$\begin{array}{c}\text { Column (2) } \\
\begin{array}{c}\text { Path } a \\
\text { education }\end{array}\end{array}$} & \multirow{2}{*}{$\begin{array}{l}\text { Column (3) } \\
\text { Path } b\end{array}$} & \multirow{2}{*}{$\begin{array}{c}\text { Column (4) } \\
\begin{array}{l}\text { Path } c^{\prime} \\
\text { income }\end{array}\end{array}$} & \multirow{2}{*}{$\begin{array}{c}\text { Column (5) } \\
\begin{array}{c}\text { Path } c^{\prime} \\
\text { education }\end{array}\end{array}$} & \multicolumn{2}{|c|}{ Column (6) } & \multicolumn{2}{|c|}{ Column (7) } \\
\hline & & & & & & \multicolumn{2}{|c|}{$\begin{array}{l}\text { Mediation effect } \\
\text { income }\end{array}$} & \multicolumn{2}{|c|}{$\begin{array}{l}\text { Mediation effect } \\
\text { education }\end{array}$} \\
\hline & $B$ & $B$ & $B$ & $B$ & $B$ & $B$ & $95 \% \mathrm{Cl}$ & $B$ & $95 \% \mathrm{Cl}$ \\
\hline $\begin{array}{l}\text { Any barrier to meet the vegetable } \\
\text { guideline }\end{array}$ & 0.23 & 0.31 & $-0.42^{* \star *}$ & 0.08 & $-0.57^{\star \star}$ & -0.10 & $-0.24,0.05$ & -0.13 & $-0.27,0.01$ \\
\hline Vegetables are expensive & $0.69^{\star \star}$ & $0.58^{*}$ & -0.08 & 0.04 & $-0.65^{\star \star \star}$ & -0.06 & $-0.21,0.04$ & -0.05 & $-0.19,0.03$ \\
\hline Vegetables spoil quickly & 0.37 & 0.08 & -0.01 & -0.02 & -0.70 & -0.00 & $-0.13,0.08$ & -0.00 & $-0.08,0.06$ \\
\hline Eating vegetables is impractical & $\ddagger$ & $\ddagger$ & $\ddagger$ & $\ddagger$ & $\ddagger$ & $\ddagger$ & & $\ddagger$ & \\
\hline Difficult to find tasty vegetables & 0.26 & 0.39 & $-0.34^{\star \star \star}$ & 0.07 & $-0.57^{* *}$ & -0.09 & $-0.30,0.09$ & -0.13 & $-0.37,0.04$ \\
\hline Dislike vegetables & -0.23 & 0.39 & $-0.29^{\star \star}$ & -0.09 & $-0.58^{\star}$ & 0.06 & $-0.14,0.43$ & -0.11 & $-0.50,0.08$ \\
\hline $\begin{array}{l}\text { Recommendations for vegetables are not } \\
\text { clear }\end{array}$ & $\ddagger$ & $\ddagger$ & $\ddagger$ & $\ddagger$ & $\ddagger$ & $\ddagger$ & & $\ddagger$ & \\
\hline It is difficult to store vegetables & 0.49 & 0.22 & -0.01 & -0.02 & $-0.69^{\star \star}$ & -0.00 & $-0.13,0.08$ & -0.09 & $-0.00,0.05$ \\
\hline It takes a lot of time to prepare vegetables & -0.20 & -0.30 & -0.08 & -0.04 & $-0.72^{\star \star \star}$ & 0.02 & $-0.02,0.15$ & 0.03 & $-0.02,0.18$ \\
\hline $\begin{array}{l}\text { Concerns about the pesticide residues on } \\
\text { vegetables }\end{array}$ & 0.07 & -0.08 & -0.01 & -0.02 & $-0 \cdot 70^{\star \star \star}$ & 0.00 & $-0.05,0.04$ & 0.00 & $-0.04,0.05$ \\
\hline Poor appetite & -0.10 & 0.26 & $-0.56^{\star \star \star}$ & -0.08 & $0.55^{\star \star}$ & 0.05 & $-0.20,0.33$ & -0.14 & $-0.40,0.10$ \\
\hline Troubles with chewing vegetables & 0.88 & -0.52 & -0.09 & 0.06 & $-0.74^{\star \star \star}$ & -0.08 & $-0.60,0.14$ & 0.05 & $-0.11,0.47$ \\
\hline Eating out often & -0.79 & -0.17 & -0.19 & -0.17 & $-0.73^{\star \star \star}$ & 0.15 & $-0.03,0.54$ & 0.03 & $-0.07,0.29$ \\
\hline $\begin{array}{l}\text { Persons with whom I eat do not like } \\
\text { vegetables }\end{array}$ & 0.49 & 0.28 & -0.16 & 0.06 & $-0.65^{\star \star \star}$ & -0.08 & $-0.41,0.02$ & -0.04 & $-0.31,0.05$ \\
\hline \multicolumn{10}{|l|}{ Age-related barriers } \\
\hline Depressive symptoms & 0.00 & -0.02 & -0.99 & -0.02 & $-0.72^{\star \star \star}$ & -0.00 & $-0.80,0.55$ & -0.01 & $-0.09,0.03$ \\
\hline Walk disability & $0.68^{\star \star}$ & 0.24 & -0.01 & -0.01 & $-0.69^{\star \star \star}$ & -0.01 & $-0.13,0.11$ & -0.00 & $-0.08,0.04$ \\
\hline Co-morbidity & -0.21 & 0.05 & 0.08 & -0.01 & $-0.70^{\star \star \star}$ & -0.02 & $-0.11,0.02$ & -0.00 & $-0.03,0.08$ \\
\hline
\end{tabular}

SES, socio-economic status.

Statistical significance of the associations: ${ }^{*} P<0.05,{ }^{* *} P<0.01,{ }^{* *} P<0.001$

†All analyses were adjusted for sex, age, alcohol consumption, partner status and the other SES indicator.

$\ddagger$ Too few observations to perform mediation analyses.

Table 8 Associations of income and education levels with perceived barriers to adherence to the fish guideline (a path), associations of perceived barriers with adherence to the fish guideline adjusted for the SES indicators $(b$ path) $\dagger$, association of income and education levels with adherence to the fish guideline adjusted for the perceived barriers ( $c^{\prime}$ path) and the mediation effects for income and education levels in 1013 older Dutch participants of the Longitudinal Aging Study Amsterdam

\begin{tabular}{|c|c|c|c|c|c|c|c|c|c|}
\hline & \multirow{2}{*}{$\frac{\text { Column (1) }}{\begin{array}{c}\text { Path } a \\
\text { income }\end{array}}$} & \multirow{2}{*}{$\frac{\text { Column (2) }}{\begin{array}{c}\text { Path } a \\
\text { education }\end{array}}$} & \multirow{2}{*}{$\begin{array}{c}\text { Column (3) } \\
\text { Path } b\end{array}$} & \multirow{2}{*}{$\frac{\text { Column (4) }}{\begin{array}{l}\text { Path } c^{\prime} \\
\text { income }\end{array}}$} & \multirow{2}{*}{$\begin{array}{c}\text { Column (5) } \\
\text { Path } c^{\prime} \\
\text { education }\end{array}$} & \multicolumn{2}{|c|}{ Column (6) } & \multicolumn{2}{|c|}{ Column (7) } \\
\hline & & & & & & \multicolumn{2}{|c|}{$\begin{array}{l}\text { Mediation effect } \\
\text { income }\end{array}$} & \multicolumn{2}{|c|}{$\begin{array}{l}\text { Mediation effect } \\
\text { education }\end{array}$} \\
\hline & $B$ & $B$ & $B$ & $B$ & $B$ & $B$ & $95 \% \mathrm{Cl}$ & $B$ & $95 \% \mathrm{Cl}$ \\
\hline $\begin{array}{l}\text { Any barrier to meet the fish } \\
\text { guideline }\end{array}$ & $0.38^{\star}$ & -0.05 & $-0.40^{\star}$ & -0.23 & -0.29 & $-0 \cdot 15^{\star}$ & $-0.28,-0.02$ & 0.02 & $-0.11,0.15$ \\
\hline Fish is expensive & $0.81^{\star \star \star}$ & 0.32 & $-0 \cdot 15^{\star}$ & -0.26 & -0.22 & $-0.12^{\star}$ & $-0.26,-0.03$ & -0.05 & $-0.15,-0.00$ \\
\hline $\begin{array}{l}\text { Persons with whom I eat do not like } \\
\text { fish }\end{array}$ & 0.12 & -0.06 & $-0.43^{\star \star \star}$ & -0.33 & -0.29 & -0.05 & $-0 \cdot 29,0 \cdot 16$ & 0.03 & $-0.17,0.23$ \\
\hline Fish spoils quickly & -0.06 & 0.56 & 0.18 & -0.37 & $-0.37^{\star}$ & -0.01 & $-0.21,0.11$ & 0.10 & $-0.02,0.37$ \\
\hline $\begin{array}{l}\text { Recommendations for fish are not } \\
\text { clear }\end{array}$ & -0.03 & 0.36 & -0.05 & -0.38 & -0.25 & -0.00 & $-0.12,0.15$ & -0.02 & $-0.27,0.08$ \\
\hline Fish bones are unpalatable & 0.30 & -0.13 & $-0 \cdot 12$ & -0.35 & -0.28 & -0.03 & $-0.16,0.01$ & 0.02 & $-0.03,0.11$ \\
\hline Good-quality fish is hard to find & 0.22 & -0.49 & -0.02 & $-0.38^{*}$ & -0.28 & -0.00 & $-0.11,0.04$ & 0.01 & $-0.07,0.15$ \\
\hline Dislike fish & 0.21 & -0.31 & $-0.66^{\star \star \star}$ & -0.24 & $-0.47^{*}$ & -0.14 & $-0.43,0.14$ & 0.21 & $-0.79,0.16$ \\
\hline Fish smells unpalatable & -0.11 & 0.20 & $-0.42^{\star \star \star}$ & $-0.43^{*}$ & -0.18 & 0.05 & $-0.16,0.25$ & -0.09 & $-0.33,0.12$ \\
\hline Difficult to store fish & 0.54 & 0.31 & 0.05 & $-0.41^{\star}$ & -0.28 & 0.03 & $-0.08,0.18$ & 0.02 & $-0.04,0.15$ \\
\hline $\begin{array}{l}\text { Concerns about unwanted } \\
\text { materials in fish }\end{array}$ & 0.02 & -0.20 & -0.03 & $-0.38^{\star}$ & -0.27 & -0.00 & $-0.10,0.06$ & 0.01 & $-0.82,0.38$ \\
\hline It is difficult to prepare fish & -0.21 & 0.11 & -0.27 & -0.43 & -0.24 & 0.06 & $-0.08,0.27$ & -0.03 & $-0.22,0.11$ \\
\hline Poor appetite & 0.49 & 0.35 & $-0.39^{\star \star \star}$ & -0.19 & -0.13 & -0.19 & $-0.53,0.07$ & -0.14 & $-0.49,0.12$ \\
\hline Habits and tradition & 0.05 & -0.21 & $-0.48^{\star \star *}$ & $-0.36^{\star}$ & -0.36 & -0.02 & $-0.19,0.16$ & 0.10 & $-0.08,0.28$ \\
\hline \multicolumn{10}{|l|}{ Age-related barriers } \\
\hline Depressive symptoms & 0.15 & 0.39 & 0.03 & $-0.38^{*}$ & -0.28 & 0.00 & $-0.03,0.08$ & 0.01 & $-0.04,0.11$ \\
\hline Walk disability & $0.68^{\star *}$ & 0.23 & -0.05 & -0.35 & -0.26 & -0.03 & $-0.17,0.06$ & -0.01 & $-0.12,0.02$ \\
\hline Co-morbidity & -0.21 & 0.05 & 0.03 & $-0.37^{\star}$ & -0.27 & -0.01 & $-0.09,0.02$ & 0.00 & $-0.03,0.05$ \\
\hline
\end{tabular}

SES, socio-economic status.

Statistical significance of the associations: ${ }^{\star} P<0.05,{ }^{\star \star} P<0.01,{ }^{\star \star \star} P<0.001$.

†All analyses were adjusted for sex, age, alcohol consumption, partner status and the other SES indicator. 
$B=-0.15, P=0.03)$ and by the barrier 'fish is expensive' (mediation effect: $B=-0.12, P=0.03$ ). We found no mediation effects for experiencing any barrier towards the vegetable guideline and adherence to the vegetable guideline. Experiencing any barrier to meet the vegetable guideline had only marginal impact on the association between level of education and adherence to the vegetable guideline $\left(c^{\prime}\right)$ and this mediation effect was not statistically significant.

When we adjusted the associations between the SES indicators and adherence to the guidelines for the statistically significant mediators (path $c^{\prime}=$ column (4) and column (5) in Tables 6, 7 and 8), the observed associations diminished and became non-significant, which confirms the statistically significant mediation effects that we showed. Exclusion of the barriers 'dislike fruit' and 'fish is expensive' from the composed barriers 'perceiving any barrier to meet the fruit/ fish guideline' did not change the mediation results.

\section{Discussion}

The present study is the first to show that previously observed SES differences in dietary adherence are mediated by barriers to meet the fruit and fish guidelines in older Dutch adults. Our study has several main findings. First of all, perceiving any barriers to meet the guidelines was common, $48.9 \%$ of the respondents perceived a barrier to meet the fruit guideline, $40.0 \%$ for the vegetable guideline and $51 \cdot 1 \%$ perceived a barrier to meet the fish guidelines. The most frequently perceived barriers in the overall sample concerned the high price of fruit and fish and a poor appetite for adherence to the vegetable guideline. Furthermore, lower-SES groups adhered less often to the dietary guidelines and were more likely to perceive barriers. Lastly, perceiving any barrier to meet the fruit or the fish guideline and the barriers 'dislike fruit' and 'fish is expensive' were mediators and partly explained the findings why lower-income groups adhere less often to the fruit and fish guidelines.

In our study, we found that a lower education was independently associated with a lower adherence to the vegetable guideline and that a lower household income was independently associated with a lower adherence to the fruit and fish guideline. These SES inequalities in diet have been documented in the literature ${ }^{(10,11,36)}$, also among older adults ${ }^{(12,13)}$. These results motivate the aim of our study to investigate the potential pathways through which these SES indicators influence dietary adherence in older adults.

The most frequently perceived barriers in the overall sample concerned the high price of fruit and fish. This is in accordance with results in younger adults where the cost of food is related to its nutritional quality, with lower priced products being nutritionally poor and more energy dense $v$. higher priced products being nutritionally rich and less energy dense ${ }^{(37,38)}$.
To our knowledge, no previous study in older adults has focused on barriers that can explain SES differences in diet quality by performing mediation analyses. In the present study, we found evidence for mediating barriers in the associations between SES and adherence to the guidelines. Reporting any barrier to meet the fruit guideline and the barrier 'dislike fruit' partly explained the income differences in adherence to the fruit guideline. Taste is known to be an important factor in food choices ${ }^{(16,39,40)}$. A study in older adults showed that higher intakes of fruit were associated with a greater liking of fruit ${ }^{(23)}$. Information is limited in relation to whether taste preferences vary by SES, but our finding may provide information on one of the underlying mechanisms. Having a higher income may increase the possibility to try different fruits, leading to a wider taste for different fruits. Trying new fruits represents a risk of waste that lower-income individuals cannot afford to take ${ }^{(41,42)}$. Interventions aiming to increase liking of fruit may be beneficial to lower-income groups and have been found to result in improvements in fruit consumption among younger adults ${ }^{(43)}$.

Perceiving any barrier to meet the fish guideline and the barrier 'fish is expensive' partly explained the income difference in adherence to the fish guideline. Price concerns as mediating barriers are supported by the literature among younger adults, where diet costs significantly mediated the link between income and diet quality in American adults $^{(44)}$. A recent study in adults from Finland showed that price partly mediated the effects of SES indicators on the intake of fruit and vegetables ${ }^{(45)}$. Studies in adults from Australia and America also provide evidence that SES differences in food cost concerns represented part of the pathway through which SES influenced dietary outcomes $^{(46,47)}$. It is reasonable to assume that a lower income affects older people's food choice, especially with regard to fish, since it is known that especially fish is perceived to be expensive ${ }^{(48)}$. A study in adult women showed that those with the highest income had $90 \%$ lower odds to perceive price as a barrier in fish consumption ${ }^{(49)}$. Drewnoski confirmed this finding and compared the costs of different foods relative to their energy and nutritive value, showing that fish was responsible for the highest costs per serving ${ }^{(37)}$. An important question is whether removal of the price barriers leads to a higher intake and better adherence to the fish guideline. Recent studies showed that a price discount on fruit and vegetables increased the purchase of fruit and vegetables, especially in low-SES groups ${ }^{(50-52)}$. However, it remains unknown whether price reductions will also lead to an increased fish intake in older adults.

In our study, the association between level of education and adherence to the vegetable guidelines was not mediated by any barrier. A possible explanation could be that fewer barriers were perceived for adherence to the vegetable guidelines. Additionally, price was the most perceived barrier and price is known to be more closely 
related to income than to education ${ }^{(44)}$. Education is known to be more related to attitudes towards healthy eating $^{(36)}$ and knowledge about healthy eating ${ }^{(19,46)}$.

A greater proportion of the participants adhered to the fruit guidelines than to the vegetable guidelines $(82.5 \% v$. $65.1 \%$, respectively), while perceiving any fruit barrier was actually more common (48.9\%) than perceiving any vegetable barrier ( $40 \cdot 0 \%$ ). Although this suggests a contradictory finding, it can be explained. The higher adherence to the fruit guideline may in part be the consequence of the fact that a maximum of one piece of fruit per day can be replaced by one glass of fruit juice. This is in accordance with the Dutch dietary guidelines, but it is possible that not all respondents were aware of this and therefore underestimated their adherence to the fruit guideline and perceived more barriers. Another explanation may be that vegetables are more versatile than fruit. Vegetables can be eaten as part of the meal, or in hotchpotches, soups or as a salad. People can choose from many options, while the methods of preparation for fruit are more limited. This could lead to a smaller number of perceived barriers for meeting the vegetable guideline than for the fruit guideline.

Also, the age-related barriers, measured by health and physical variables, did not mediate any of the associations between SES and adherence to the dietary guidelines suggesting that these barriers are of little interest in explaining SES differences. This may seem surprising as health status is known to differ according to SES group and plays an important role in food choices ${ }^{(16)}$. Since no other studies have investigated age-related barriers as mediators in the association between SES and adherence to guidelines we can only speculate about explanations for this finding. Dietary resilience is a new concept that explains how some older adults eat well despite age-related changes. Food-related motivations, such as the availability of support and the willingness to draw on this support, may contribute to dietary resilience ${ }^{(53)}$, but future research must find out how dietary resilience is related to SES.

Our study has several strengths. It is the first study that focused on the mediating role of barriers to explain SES differences in adherence to the dietary guidelines in older adults. It extends findings from previous research that showed associations between SES and adherence to the guidelines. The LASA evaluates a large sample of community-dwelling older adults who were selected on the basis of having a good cognitive status, which has the advantage that recall bias due to poor cognitive functioning with regard to dietary intake and other selfreported data is lower. The well-characterized design of LASA enabled us to investigate a broad range of perceived barriers by older adults as well as potential age-related barriers and to adjust for relevant confounders. We also included two measures of SES in our models, which allows a clearer assessment of the SES indicator in question and its association with diet quality. Limitations should be noted as well. The cross-sectional design of the study limits the ability to infer a causal relationship or its direction. Nevertheless, SES is more likely to influence adherence to the dietary guidelines and the barriers for adherence than vice versa. Another potential limitation is that the nutritional assessment method followed, although used widely, has not yet been validated in older adults and so potential reporting bias cannot be excluded. However, an FFQ is a frequently used tool to assess dietary intake among large samples and allows older adults to answer questions related to their diet relatively quickly and easily. Finally, many of the barriers to meet the fruit, vegetable and fish guidelines differed across SES groups, but did not mediate the association between SES and dietary adherence. Some of the barriers were mentioned by only a small proportion of the respondents and the categories became very small and reduced our power. Respondents were instructed to report a maximum of two barriers. This was done to obtain information on the most relevant experiences by our respondents. However, due to this restriction some of the barriers may have been reported less frequently and we cannot exclude that additional mediation pathways may be overlooked by our answer restriction.

\section{Conclusion}

The findings of the present large-scale study in older Dutch adults suggest that focusing on barriers to meet the fruit and fish guidelines, and in particular taste preferences and cost concerns, may be important in reducing income inequalities in fruit and fish intakes among older adults. Affordable and accessible healthy foods, and interventions aimed at improving liking of fruits, could potentially increase fruit and fish intakes, especially in populations with lower incomes. Studies in older persons should be conducted to test whether removal of these barriers in fact leads to better dietary adherence.

\section{Acknowledgements}

Financial support: The Longitudinal Aging Study Amsterdam is largely supported by a grant from the Netherlands Ministry of Health Welfare and Sports, Directorate of Nursing Care and Older persons. This research received no specific grant from any funding agency in the public, commercial or notfor-profit sectors. Conflict of interest: None. Authorship: S.C.D. performed complete data analyses, writing of the first draft of the manuscript and revision of the manuscript. M.V. contributed to the design of the study and participated in data collection. D.L.K. provided statistical advice concerning the mediation analyses. J.E.N., M.M.v.S., M.H., I.A.B. and M.V. provided significant advice concerning interpretation of the results and critical review of the manuscript. All authors were involved in the development of the manuscript and 
approved the final manuscript. Ethics of buman subject participation: The study was approved by the Medical Ethical Committee of the VU University Medical Center (Amsterdam, the Netherlands).

\section{References}

1. Gallo V, Mackenbach JP, Ezzati M et al. (2012) Social inequalities and mortality in Europe - results from a large multi-national cohort. PLoS One 7, e39013.

2. Huisman M, Read S, Towriss CA et al. (2013) Socioeconomic inequalities in mortality rates in old age in the World Health Organization Europe Region. Epidemiol Rev (Epublication ahead of print version).

3. Anderson AL, Harris TB, Tylavsky FA et al. (2011) Dietary patterns and survival of older adults. J Am Diet Assoc 111, 84-91.

4. Zheng J, Huang T, Yu Y et al. (2012) Fish consumption and CHD mortality: an updated meta-analysis of seventeen cohort studies. Public Health Nutr 15, 725-737.

5. Bellavia A, Larsson S, Bottai M et al. (2013) Fruit and vegetable consumption and all-cause mortality: a dose-response analysis. Am J Clin Nutr 98, 454-459.

6. He FJ, Nowson CA, Lucas M et al. (2007) Increased consumption of fruit and vegetables is related to a reduced risk of coronary heart disease: meta-analysis of cohort studies. $J$ Hum Hypertens 21, 717-728.

7. Alinia S, Hels O \& Tetens I (2009) The potential association between fruit intake and body weight - a review. Obes Rev 10, 639-647.

8. Carter P, Gray LJ, Troughton J et al. (2010) Fruit and vegetable intake and incidence of type 2 diabetes mellitus: systematic review and meta-analysis. BMJ 341, c4229.

9. Romaguera D, Vergnaud AC, Peeters PH et al. (2012) Is concordance with World Cancer Research Fund/American Institute for Cancer Research guidelines for cancer prevention related to subsequent risk of cancer? Results from the EPIC study. Am J Clin Nutr 96, 150-163.

10. Malon A, Deschamps V, Salanave B et al. (2010) Compliance with French nutrition and health program recommendations is strongly associated with socioeconomic characteristics in the general adult population. J Am Diet Assoc 110, 848-856.

11. Giskes K, Turrell G, van Lenthe FJ et al. (2006) A multilevel study of socio-economic inequalities in food choice behaviour and dietary intake among the Dutch population: the GLOBE study. Public Health Nutr 9, 75-83.

12. van Rossum CT, van de Mheen H, Witteman JC et al. (2000) Education and nutrient intake in Dutch elderly people. The Rotterdam Study. Eur J Clin Nutr 54, 159-165.

13. Dijkstra SC, Neter JE, Brouwer IA et al. (2014) Adherence to dietary guidelines for fruit, vegetables and fish among older Dutch adults; the role of education, income and job prestige. J Nutr Health Aging 18, 115-121.

14. Brug J, de Vet E, de Nooijer J et al. (2006) Predicting fruit consumption: cognitions, intention, and habits. J Nutr Educ Behav 38, 73-81.

15. Marcy TR, Britton ML \& Harrison D (2011) Identification of barriers to appropriate dietary behavior in low-income patients with type 2 diabetes mellitus. Diabetes Ther 2, 9-19.

16. Schatzer M, Rust P \& Elmadfa I (2010) Fruit and vegetable intake in Austrian adults: intake frequency, serving sizes, reasons for and barriers to consumption, and potential for increasing consumption. Public Health Nutr 13, 480-487.

17. Van Duyn MA, Kristal AR, Dodd K et al. (2001) Association of awareness, intrapersonal and interpersonal factors, and stage of dietary change with fruit and vegetable consumption: a national survey. Am J Health Promot 16, 69-78.
18. Haynes-Maslow L, Parsons SE, Wheeler SB et al. (2013) A qualitative study of perceived barriers to fruit and vegetable consumption among low-income populations, North Carolina, 2011. Prev Chronic Dis 10, E34.

19. McLeod ER, Campbell KJ \& Hesketh KD (2011) Nutrition knowledge: a mediator between socioeconomic position and diet quality in Australian first-time mothers. J Am Diet Assoc 111, 696-704.

20. Hughes G, Bennett KM \& Hetherington MM (2004) Old and alone: barriers to healthy eating in older men living on their own. Appetite 43, 269-276.

21. Holmes BA \& Roberts CL (2011) Diet quality and the influence of social and physical factors on food consumption and nutrient intake in materially deprived older people. Eur J Clin Nutr 65, 538-545.

22. Donini LM, Savina C \& Cannella C (2003) Eating habits and appetite control in the elderly: the anorexia of aging. Int Psychogeriatr 15, 73-87.

23. Appleton KM, McGill R, Neville C et al. (2010) Barriers to increasing fruit and vegetable intakes in the older population of Northern Ireland: low levels of liking and low awareness of current recommendations. Public Health Nutr 13, 514-521.

24. Huisman M, Poppelaars J, van der Horst M et al. (2011) Cohort profile: the Longitudinal Aging Study Amsterdam. Int J Epidemiol 40, 868-876.

25. Krieger N, Williams DR \& Moss NE (1997) Measuring social class in US public health research: concepts, methodologies, and guidelines. Annu Rev Public Health 18, 341-378.

26. Planbureau C (2014) Modaal inkomen. http://www.cpb.nl/ onderwerp/arbeidsmarkt (accessed March 2014).

27. Koster A, Bosma H, Broese van Groenou MI et al. (2006) Explanations of socioeconomic differences in changes in physical function in older adults: results from the Longitudinal Aging Study Amsterdam. BMC Public Health 6, 244.

28. Nieuwenhuizen WF, Weenen H, Rigby P et al. (2010) Older adults and patients in need of nutritional support: review of current treatment options and factors influencing nutritional intake. Clin Nutr 29, 160-169.

29. Shaikh AR, Yaroch AL, Nebeling L et al. (2008) Psychosocial predictors of fruit and vegetable consumption in adults a review of the literature. Am J Prev Med 34, 535-543.

30. Radloff L (1997) The CES-D scale: a self-report depression scale for research in the general population. Appl Psychol Meas 1, 385-401.

31. Berkman L, Berkman C \& Kasl S et al. (1986) Depressive symptoms in relation to physical health and functioning in the elderly. Am J Epidemiol 124, 372-388.

32. Block G, Gillespie C, Rosenbaum EH et al. (2000) A rapid food screener to assess fat and fruit and vegetable intake. Am J Prev Med 18, 284-288.

33. Kim DJ \& Holowaty EJ (2003) Brief, validated survey instruments for the measurement of fruit and vegetable intakes in adults: a review. Prev Med 36, 440-447.

34. Stel V, Smit J, Pluijm S et al. (2004) Comparison of the LASA Physical Activity Questionnaire with a 7-day diary and pedometer. J Clin Epidemiol 57, 252-258.

35. Mackenbach JP \& Kunst AE (1997) Measuring the magnitude of socio-economic inequalities in health: an overview of available measures illustrated with two examples from Europe. Soc Sci Med 44, 757-771.

36. Le J, Dallongeville J, Wagner A et al. (2013) Attitudes toward healthy eating: a mediator of the educational level-diet relationship. Eur J Clin Nutr 67, 808-814.

37. Drewnowski A (2010) The cost of US foods as related to their nutritive value. Am J Clin Nutr $92,1181-1188$.

38. Darmon N, Darmon M, Maillot M et al. (2005) A nutrient density standard for vegetables and fruits: nutrients per calorie and nutrients per unit cost. J Am Diet Assoc 105, 1881-1887. 
39. Baker AH \& Wardle J (2003) Sex differences in fruit and vegetable intake in older adults. Appetite 40, 269-275.

40. Lancaster KJ (2004) Characteristics influencing daily consumption of fruits and vegetables and low-fat dairy products in older adults with hypertension. J Nutr Elder 23, 21-33.

41. Dye CJ \& Cason KL (2005) Perceptions of older, low-income women about increasing intake of fruits and vegetables. J Nutr Elder 25, 21-41.

42. Glasson C, Chapman K \& James E (2011) Fruit and vegetables should be targeted separately in health promotion programmes: differences in consumption levels, barriers, knowledge and stages of readiness for change. Public Health Nutr 14, 694-701.

43. Anderson AS (2007) Nutrition interventions in women in low-income groups in the UK. Proc Nutr Soc 66, 25-32.

44. Aggarwal A, Monsivais P, Cook AJ et al. (2011) Does diet cost mediate the relation between socioeconomic position and diet quality? Eur J Clin Nutr 65, 1059-1066.

45. Konttinen H, Sarlio-Lahteenkorva S, Silventoinen $\mathrm{K}$ et al. (2013) Socio-economic disparities in the consumption of vegetables, fruit and energy-dense foods: the role of motive priorities. Public Health Nutr 16, 873-882.

46. Turrell G \& Kavanagh AM (2006) Socio-economic pathways to diet: modelling the association between socio-economic position and food purchasing behaviour. Public Health Nutr 9, 375-383
47. Beydoun MA \& Wang Y (2008) How do socio-economic status, perceived economic barriers and nutritional benefits affect quality of dietary intake among US adults? Eur J Clin Nutr 62, 303-313.

48. Grieger JA, Miller M \& Cobiac L (2012) Knowledge and barriers relating to fish consumption in older Australians. Appetite 59, 456-463.

49. Trondsen T, Scholderer J, Lund E et al. (2003) Perceived barriers to consumption of fish among Norwegian women. Appetite 41, 301-314.

50. Geliebter A, Ang IYH, Bernales-Korins M et al. (2013) Supermarket discounts of low-energy density foods: effects on purchasing, food intake, and body weight. Obesity (Silver Spring) 21, E542-E548.

51. Waterlander WE, de Boer MR, Schuit AJ et al. (2013) Price discounts significantly enhance fruit and vegetable purchases when combined with nutrition education: a randomized controlled supermarket trial. Am J Clin Nutr $\mathbf{9 7}$, 886-895.

52. Green R, Cornelsen L, Dangour AD et al. (2013) The effect of rising food prices on food consumption: systematic review with meta-regression. BMJ 346, f3703.

53. Vesnaver E, Keller HH, Payette $\mathrm{H}$ et al. (2012) Dietary resilience as described by older community-dwelling adults from the NuAge study 'if there is a will - there is a way!'. Appetite 58, 730-738. 